\title{
Effects of initial conditions in operational modal analysis
}

\author{
Shiqiang Qin ${ }^{1,2, *, \dagger}$, Edwin Reynders ${ }^{1}$, Leqia $\mathrm{He}^{1}$, TienThanh Bui ${ }^{1}$ and Guido De Roeck ${ }^{1}$ \\ ${ }^{1}$ Department of Civil Engineering, University of Leuven (KU Leuven), B-3001 Leuven, Belgium \\ ${ }^{2}$ School of Civil Engineering, Southwest Jiaotong University, 610031 Chengdu, China
}

\begin{abstract}
SUMMARY
In this study, the effects of high-amplitude initial conditions on the accuracy of modal parameters, identified from output-only vibration data, are investigated. The influence on the sample output correlation function, which is the basis of most time-domain operational modal analysis techniques, is analyzed first. Then, a numerical simulation is performed to quantify the effect of nonzero initial conditions on the relative accuracy of natural frequencies, damping ratios, and mode shapes. It is shown that, when all identification assumptions are satisfied, high-amplitude initial conditions can significantly reduce the estimation errors, especially for short data records. Finally, a full-scale application is presented where the modal parameters of a six-span high-speed railway bridge are determined from output-only data. The results obtained with two different data sets are compared: The first one consists of the bridge's response to ambient data only, whereas the second one also contains the free vibration recorded immediately after a train passage. Although for most modes the results are similar, it is possible to identify some additional bending and torsion modes from the free vibration data with good accuracy. Copyright (c) 2013 John Wiley \& Sons, Ltd.
\end{abstract}

Received 22 November 2012; Revised 25 March 2013; Accepted 8 May 2013

KEY WORDS: operational modal analysis; initial condition; stochastic subspace identification; ambient vibration test; free vibration response; output covariance

\section{INTRODUCTION}

There is much practical interest in SHM of civil structures based on vibration measurements, and in recent years, much research effort has been spent in the search for robust approaches [1-6]. By placing sensors on a structure and monitoring the structural dynamic behavior, SHM provides an attractive solution to operational safety and management of civil structures. SHM also provides an experimental method to study structural behavior under extreme loading conditions (e.g., earthquake and hurricane). Several successful applications of vibration-based SHM systems in civil structures have been reported recently [7-13].

The SHM is a nondestructive technique for damage identification that is based on tracking the changes in dynamic characteristics of a structure. Modal parameters, that is, natural frequencies, damping ratios, and mode shapes are sensitive to (some) structural changes and often serve as indicators in modal-based damage detection [14]. There are mainly two types of tests to identify modal parameters: forced vibration and ambient vibration test. When performing a forced vibration test on a civil structure, heavy actuators such as drop weights or shakers are needed, and the operational service needs to be interrupted during the test. In contrast, an ambient vibration test makes use of the operational response to freely available ambient loads (wind, traffic, micro-tremors, etc.), and it requires the structure to remain in operation. Therefore, ambient vibration tests have become very popular for determining the modal properties of large civil structures. A wide variety of successful

*Correspondence to: Shiqiang Qin, School of Civil Engineering, Southwest Jiaotong University, 610031 Chengdu, China.

${ }^{\dagger}$ E-mail: qsqiang417@gmail.com 
applications of modal analysis based on ambient vibration data, also called operational modal analysis (OMA), have been reported; see, for example, References [15-19] and the references therein.

Although OMA has been widely used in many reported case studies, it has two major drawbacks: The mode shapes cannot be mass normalized in a single test, and the response due to ambient excitation is often narrow banded in the frequency domain, so that only a limited number of lower modes can be identified with good accuracy. Nevertheless, the higher modes are often of interest as well, especially for SHM purposes because they tend to be more sensitive to local damage. For these reasons, there has been an increasing interest in OMA with exogenous inputs (OMAX) during the past years. In OMAX, both measured and unmeasured forces are taken into account, so that small and practical actuators can be used in operational conditions $[6,19,20]$. However, the OMAX approach is less well suited for permanent SHM.

In this paper, it is therefore investigated whether an output-only modal analysis starting from largeamplitude initial conditions, as opposed to the more common case of low-amplitude or zero-amplitude initial conditions, can serve as an alternative method for increasing the accuracy of the identified modal parameters and for enlarging the frequency content of the response. Such initial conditions occur, for instance, immediately after the passage of a train on a railway bridge or immediately after the passage of a heavy truck on a road bridge. It is likely that the free response induced by initial conditions has a broader frequency spectrum than the purely ambient response. The free vibration test, based on the sudden release of a heavy mass from structure, is a reliable method to determine damping ratios. The natural frequencies and mode shapes obtained from free vibration test can also serve as a check of the modal parameters extracted from ambient vibration test. Modal properties obtained from the two experimental methods are compared in References [21-23].

The basis of most time-domain system identification methods for OMA is the output correlation function. This function is estimated from the measured vibration response data by averaging over the available data samples, resulting in the sample output correlation function. The influence of the initial conditions on the sample correlation function is therefore analyzed first, in Section 2. Then, in Section 3, a numerical simulation on a single DOF (SDOF) system is performed to quantify the effect of nonzero initial conditions on the relative accuracy of natural frequencies and damping ratios. The results of this simulation are employed in the subsequent case study of Section 4. A full-scale application is presented where the modal parameters of a six-span high-speed railway bridge are determined from output-only data. In all cases, the modal parameters are identified with stochastic subspace identification (SSI) [24-26], which is chosen as a representative time-domain system identification algorithm in this paper. Simulation [19,27] and case studies [28-30] have shown that this is one of the most robust and accurate algorithms available for output-only modal analysis. Conclusions are drawn in Section 5.

\section{EFFECT OF INITIAL CONDITIONS ON OUTPUT COVARIANCE ESTIMATES}

In this section, we will theoretically analyze the output covariances with considering initial conditions. The stochastic state space model of a structure with $n$ DOFs is defined in Equation (1) [25]

$$
\begin{aligned}
x_{k+1} & =A x_{k}+w_{k} \\
y_{k} & =C x_{k}+v_{k}
\end{aligned}
$$

where $x_{k} \in \mathbb{R}^{n \times 1}$ is the state vector, and $y_{k} \in \mathbb{R}^{l \times 1}$ is the vector of output measurements. $l$ is the number of the DOFs tested. $k$ is the discrete time sample number. $A \in \mathbb{R}^{n \times n}$ and $C \in \mathbb{R}^{l \times n}$ are the state matrix and the output matrix, respectively. $w_{k} \in \mathbb{R}^{n \times 1}$ is the process noise due to modeling errors, and $v_{k} \in \mathbb{R}^{l \times 1}$ is the measurement noise due to sensor inaccuracy, both of which are assumed to be zero-mean white noise with covariance matrix:

$$
E\left[\left[\begin{array}{c}
w_{p} \\
v_{p}
\end{array}\right] \cdot\left[\begin{array}{ll}
w_{q}^{T} & v_{q}^{T}
\end{array}\right]\right]=\left[\begin{array}{cc}
Q & S \\
S^{T} & R
\end{array}\right] \cdot \delta(p-q)
$$


where $E$ is the expected value operator and $\delta_{p q}$ denotes Kronecker delta. The output covariance matrix is defined as

$$
\Lambda_{i}=E\left[\begin{array}{ll}
y_{k}+i & y_{k}^{T}
\end{array}\right]=\lim _{N \rightarrow \infty} \frac{1}{N} \sum_{k=0}^{N} y_{k}+i y_{k}^{T}
$$

where $N$ represents the total number of discrete data samples. In a real test, $N$ is a finite number, so the output covariance matrices $\Lambda_{i}$ cannot be calculated exactly. Instead, the estimate $\hat{\Lambda}_{i}$ is obtained:

$$
\hat{\Lambda}_{i}=\frac{1}{N} \sum_{k=0}^{N} y_{k}+i y_{k}^{T} .
$$

When considering $k=1,2$ for the output vector $y_{k}$ in Equation (1), we obtain following expressions of $y_{1}$ and $y_{2}$ :

$$
\begin{aligned}
y_{1} & =C x_{1}+v_{1} \\
& =C\left(A x_{0}+w_{0}\right)+v_{1} \\
& =C A x_{0}+C w_{0}+v_{1} \\
y_{2} & =C x_{2}+v_{2} \\
& =C\left(A x_{1}+w_{1}\right)+v_{2} \\
& =C A^{2} x_{0}+C A w_{0}+C w_{1}+v_{2}
\end{aligned}
$$

Generalizing this result to arbitrary values of $k$ yields

$$
y_{k}=C A^{k} x_{0}+\sum_{m=1}^{k} C A^{k-m} w_{m-1}+v_{k}
$$

where $m$ is a positive integer. $x_{0}$ represents the initial conditions at the start of the measurements. Equation (7) shows that the output is composed of two parts. The first part, denoted by $y_{k}^{\text {ini }}$, contains the influence of the initial condition, whereas the second part, denoted by $y_{k}^{\text {amb }}$, is due to the ambient excitation:

$$
\begin{aligned}
& y_{k}^{\mathrm{ini}}=C A^{k} x_{0} \\
& y_{k}^{\mathrm{amb}}=\sum_{m=1}^{k} C A^{k-m} w_{m-1}+v_{k}
\end{aligned}
$$

where the superscript ini stands for initial and amb represents ambient. Through Equations (7) and (8), the estimate of output covariance matrices $\hat{\Lambda}_{i}$ can be rewritten as follows:

$$
\begin{aligned}
\hat{\Lambda}_{i} & =\frac{1}{N_{k}} \sum_{k=0}^{N-i} y_{k+i} y_{k}^{T} \\
& =\frac{1}{N_{k}} \sum_{=0}^{N-i}\left(y_{k}^{\mathrm{ini}}+i+y_{k+i}^{\mathrm{amb}}\right)\left(y_{k}^{\mathrm{ini}}+y_{k}^{\mathrm{amb}}\right)^{T}
\end{aligned}
$$

Let us now consider the following two limit situations.

Case 1: Zero initial condition and nonzero ambient excitation. In this situation, the output covariance can be estimated as follows:

$$
\hat{\Lambda}_{i}=\hat{\Lambda}_{i}^{\mathrm{amb}}=\frac{1}{N} \sum_{k=0}^{N-i} y_{k+i}^{\mathrm{amb}} y_{k}^{\mathrm{amb}^{T}}
$$

For a small number of data samples, the accuracy of $\hat{\Lambda}_{i}^{\text {amb }}$ is relatively low. However, 
Equation (10) converges to the following expression when the number of data samples $N$ is increased:

$$
\begin{aligned}
& \Lambda_{i}^{\mathrm{amb}}=\lim _{N \rightarrow \infty} \hat{\Lambda}_{i}^{\mathrm{amb}}=\lim _{N \rightarrow \infty} \frac{1^{N}}{N} \sum_{k=0}^{i}\left(C x_{k}^{\mathrm{amb}}+i+v_{k}+i\right) y_{k}^{\mathrm{amb}}
\end{aligned}
$$

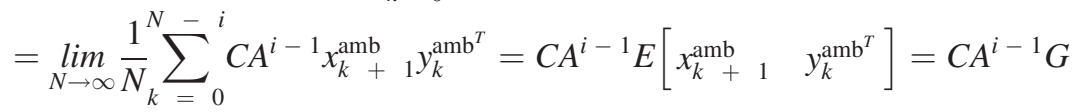

where $\boldsymbol{G}$ represents the next state-output covariance matrix. Equation (11) is the basis for stochastic system realization or SSI methods. Such methods estimate the system matrices $\boldsymbol{C}, \boldsymbol{A}$, and $\boldsymbol{G}$ from the decomposition of the estimate $\hat{\Lambda}_{i}^{\mathrm{amb}}$ of the output correlation sequence. When the number of samples $N$ increases to infinity, the estimate $\hat{\Lambda}_{i}^{\text {amb }}$ converges to the exact matrix $\Lambda_{i}^{\mathrm{amb}}$, and as a consequence, the estimates of the system matrices converge to their true values.

Case 2: Zero ambient excitation and nonzero initial conditions. In this situation, the output covariances are estimated from the pure free vibration responses under initial conditions. From Equation (9), we obtain

$$
\begin{aligned}
\hat{\Lambda}_{i}=\Lambda_{i, N}^{\mathrm{det}} & =\frac{1}{N} \sum_{k=0}^{N-i} C A^{k+i} x_{0} x_{0}^{T} A^{k^{T}} C^{T} \\
& =C A^{i-1} \frac{1}{N} \sum_{k=0}^{N-i} A^{k+1} x_{0} x_{0}^{T} A^{k^{T}} C^{T}
\end{aligned}
$$

The superscript det emphasizes that $\Lambda_{i, N}^{\operatorname{det}}$ is purely deterministic. $\Lambda_{i, N}^{\operatorname{det}}$ depends on the number of samples $N$. It converges to zero when $N$ tends to infinity. From the last equality in Equation (12), it follows that the matrices $\boldsymbol{A}$ and $\boldsymbol{C}$ can be determined exactly with a stochastic system identification method from the output correlation sequence for finite $N$. This can, for instance, be achieved with stochastic system realization or subspace identification algorithms, which have become standard tools in OMA [19].

In a real measurement situation, both ambient excitation and initial conditions are exist. The output measurements are the combination of free vibration and ambient data. Therefore, the accuracy of the output covariance estimated from the real test data is influenced by both ambient excitation and initial conditions. If the ambient excitation is dominant, then one expects a low accuracy of output covariance with a low number of data samples $N$. If the initial conditions are dominant, then one expects a much better accuracy of output covariance for a small number of data samples. We will further quantify this observation in a simulation example in the next section.

\section{SIMULATION USING A SINGLE DOF SYSTEM}

Assuming all identification assumptions are satisfied, we will study in this section the relationship between the estimation errors, the initial conditions, and the measurement duration through a numerical simulation of the simplest case possible: the OMA of a SDOF system. The numerical study is based on Monte Carlo simulation [31]. The characteristics of the system are plotted in Figure 1. The mass, stiffness, and frequency of the system are fixed, whereas two different values for the damping ratio are considered. The ambient excitation is white noise signal with a variance of 1 . The free vibration responses are obtained by giving an initial displacement to the system. Six initial displacements are studied, which are $x_{0}=0,0.001,0.0025,0.005,0.01,0.05 \mathrm{~m}$. The sampling frequency is $50 \mathrm{~Hz}$. Figure 2 plots the pure ambient vibration response and free vibration response under the initial displacement $x_{0}=0.05 \mathrm{~m}$. The maximum amplitude of the free vibration signal is around 15 times as high as that of the pure ambient signal. Under different initial displacement conditions, the 


$$
\begin{gathered}
m=2.5 \mathrm{~kg}, k=4000 \frac{\mathrm{N}}{\mathrm{m} / \mathrm{s}}, f=6.366 \mathrm{~Hz} \\
\text { case } 1: c_{1}=1 \frac{\mathrm{N}}{\mathrm{m} / \mathrm{s}}, \xi_{1}=0.5 \% \\
\quad \text { case } 2: c_{2}=3 \frac{\mathrm{N}}{\mathrm{m} / \mathrm{s}}, \xi_{2}=1.5 \%
\end{gathered}
$$

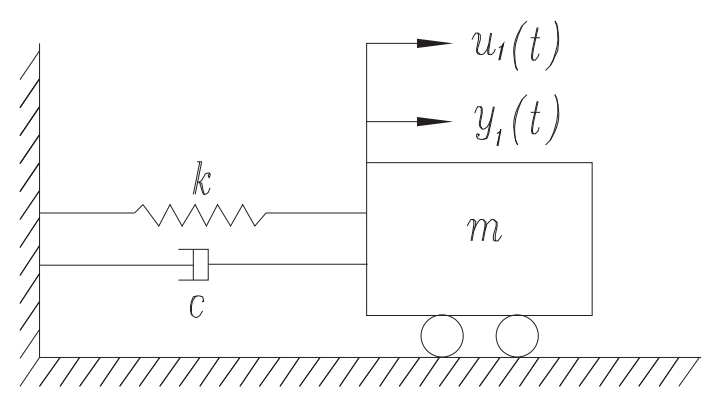

Figure 1. Description of the single DOF system.
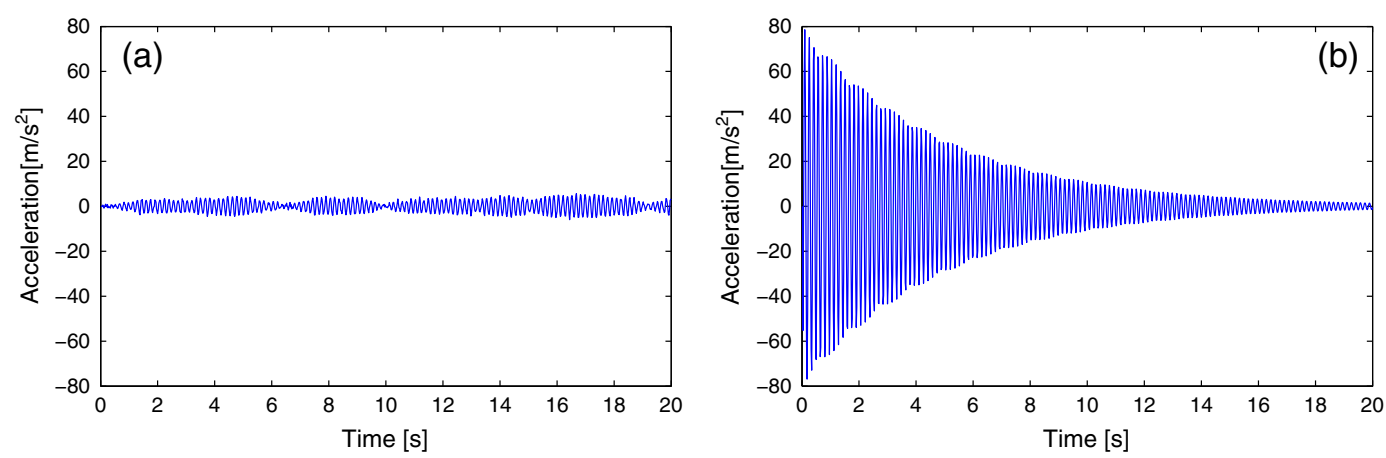

Figure 2. Acceleration time history (a) for purely ambient excitation with zero initial conditions and (b) for the free vibration with an initial displacement $x_{0}=0.05 \mathrm{~m}$ and $\xi_{1}=0.5 \%$.

amplitude of the free vibration signal varies greatly. To quantify the amplitude difference between free vibration and ambient data, we define the amplitude ratio $R$ as

$$
R=\frac{\operatorname{MAX}\left(y_{\text {free }}\right)}{\operatorname{RMS}\left(y_{\mathrm{amb}}\right)}
$$

where $y_{\text {free }}$ and $y_{\text {amb }}$ denote the free and ambient vibration responses, respectively. $\operatorname{MAX}(\bullet)$ is the function to find the maximum value. $\operatorname{RMS}(\bullet)$ is the function to calculate the root mean value of a signal. If the signal is stationary, then its RMS value is independent of its length.

The free vibration data under initial displacement are combined with pure ambient data to identify modal parameters. The modal parameters are extracted by using the SSI-cov algorithm [25]. The algorithm parameters are chosen as follows: the half-block row number $i=5$ and the model order $n=2$. The number of data samples is varied to be $N=14,15,16,2^{5}, 2^{6}, 2^{7}, 2^{8}, \ldots, 2^{16}$. The analysis is performed 500 times for each initial displacement; in each of these Monte Carlo runs, a different realization of the white noise excitation is used. The standard deviations of the eigenfrequency $\sigma_{f}$ and the damping ratio $\sigma_{\xi}$ are estimated as the sample values obtained over the 500 Monte Carlo runs.

Figure 3 plots the relative standard deviation of the eigenfrequency $\sigma_{f} / f$ in function of the number of eigenperiods for different amplitude ratios of free vibration and ambient data. The eigenperiod of the SDOF is defined by $1 / f$ with $f$ as the eigenfrequency. The number of eigenperiods is defined as the sampling time divided by eigenperiod. $\sigma_{f} / f$ is a measure of the relative accuracy of the identified eigenfrequency. Both axes of the figure are dimensionless. Many information can be obtained from this figure. First, the higher the number of eigenperiods, the more accurate the estimated eigenfrequency is. 

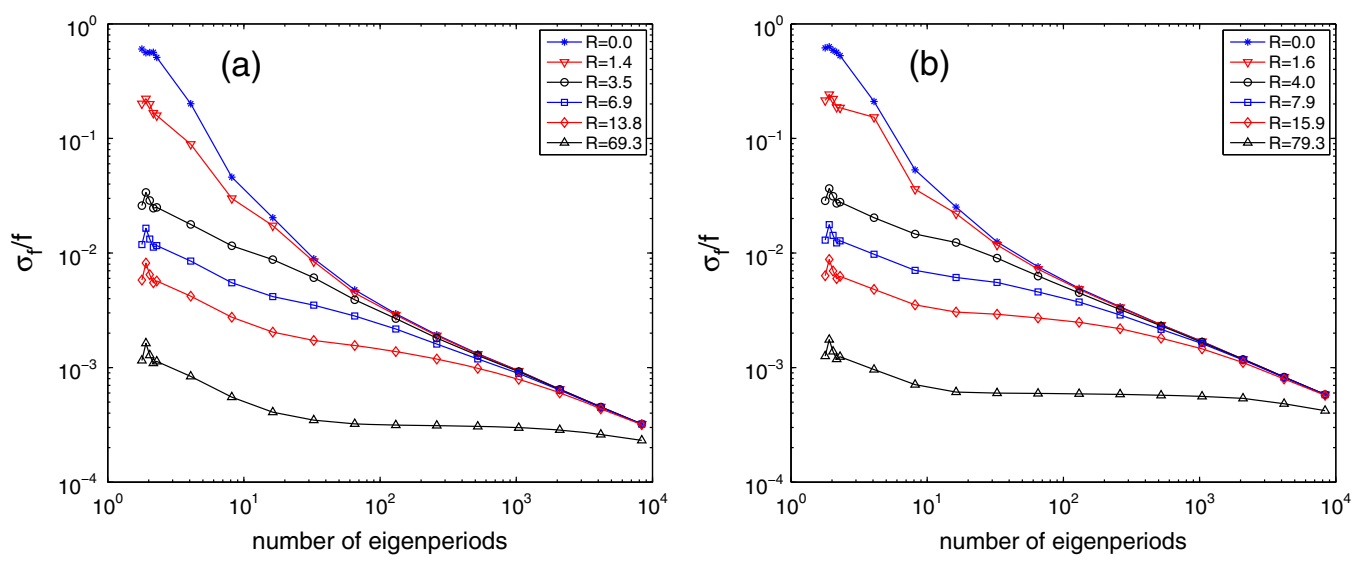

Figure 3. The relative standard deviation of the estimated eigenfrequency in function of the measurement duration. (a) $\xi_{1}=0.5 \%$ and (b) $\xi_{2}=1.5 \%$.

$\sigma_{f} / f$ is approaching zero when the number of eigenperiods goes to infinity, and no matter the frequency is identified from pure ambient data $(R=0.0)$ or from combined free and ambient data $(R>0.0)$. Second, for a fixed number of eigenperiods, the relative standard deviation of the eigenfrequency is smaller when the amplitude ratio is larger. Third, for a very low number of data samples, the relative standard deviation of the eigenfrequency that is identified from combined free-ambient data have a small increasing part, which cannot be found in the results extracted from pure ambient data. This is because at the first few samples, the free vibration dominates the response completely. Adding more data samples then leads to more inaccurate estimates as the ambient part becomes relatively more important while the number of samples is still low. Finally, for a fixed amplitude ratio, we can use the figure to find out how long the sampling time needs to be in order to attain a certain relative accuracy for the estimated eigenfrequency.

Figure 4 plots the relative standard deviation of the damping ratio $\sigma_{\xi}$ in function of the number of eigenperiods. The trend is the same as in Figure 3, but the point from where the beneficial effects of nonzero initial conditions disappear in OMA is more obvious. This is around the contraflexure point, for example, in Figure 4(b), for curve $R=7.9$, this point appears when the number of eigenperiods is 30. This is because from these contraflexure points, the ambient data start to play the dominant role, so $\sigma_{\xi}$ will start to decrease monotonically.

Figure 5 plots the relative standard deviation of the eigenfrequency and the damping ratio in function of the amplitude ratio of free vibration and ambient data. It is shown in the figure that the relative standard deviation is decreasing monotonically with increasing amplitude ratio. When the
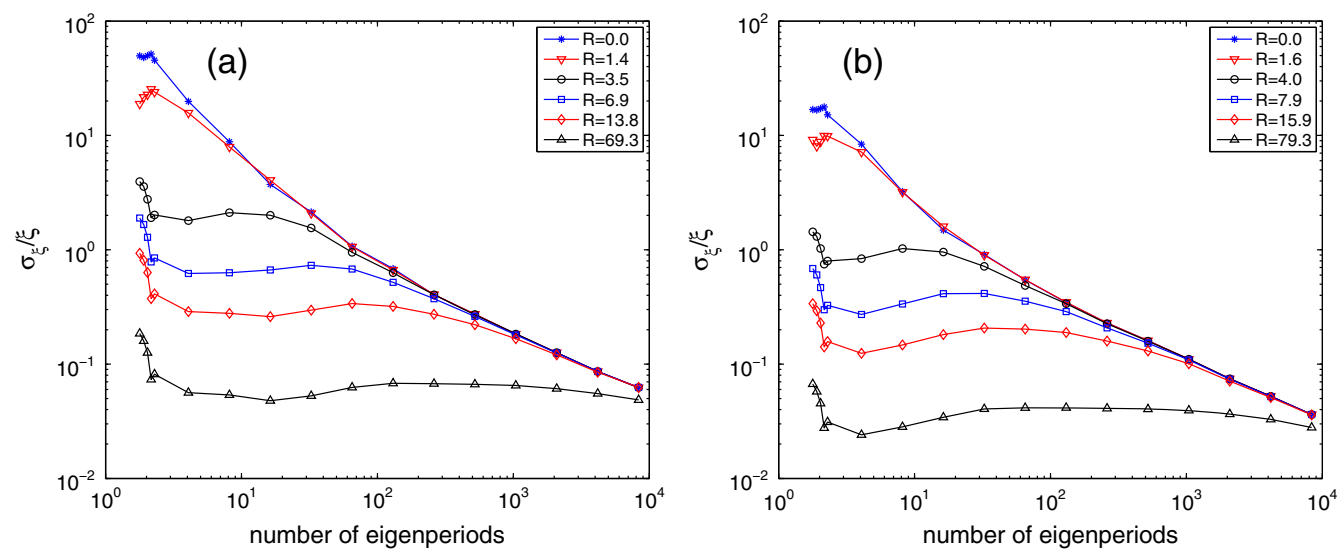

Figure 4. The relative standard deviation of the estimated damping ratio in function of the measurement duration. (a) $\xi_{1}=0.5 \%$ and (b) $\xi_{2}=1.5 \%$. 

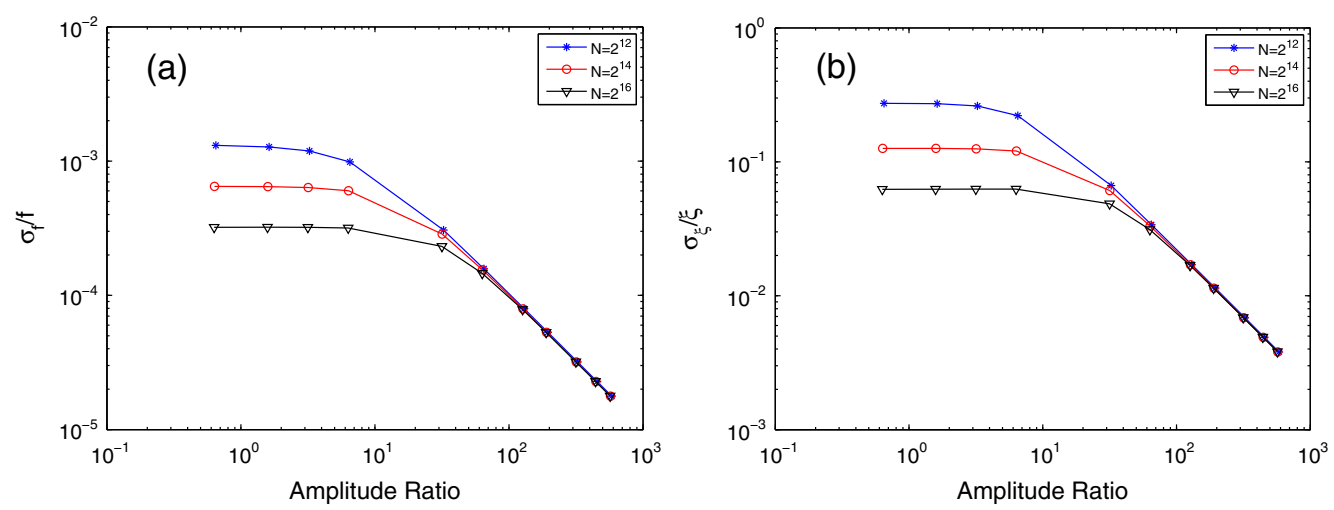

Figure 5. The relative standard deviation of (a) the eigenfrequency and (b) the damping ratio in function of the amplitude ratios.

amplitude ratio gets very large, the influence of the number of data samples on the estimation accuracy is relatively small.

As a summary, the numerical simulation illustrates that, for the ambient data, more accurate modal parameters can be obtained if we have longer sampling time (reflected also by a larger number of eigenperiods). For the combined free-ambient data, the beneficial effects of initial conditions on the accuracy of the estimated modal parameters are important for a large-amplitude ratio and a limited number of data samples. The effect disappears when the number of eigenperiods grows. The larger the amplitude ratio, the shorter the measurement duration needs to be to reach a certain accuracy. When the amplitude ratio is known or when it can be estimated, the graphs of this simulation example provide a way to estimate the sampling time needed to reach a certain target accuracy.

\section{APPLICATION: OPERATIONAL MODAL ANALYSIS OF A HIGH-SPEED RAILWAY BRIDGE}

In this section, it is illustrated how the initial conditions can influence the modal identification results of an operational vibration test. Two sets of vibration response signals are used to do the OMA: The first one contains purely ambient vibration response data, and the second one contains the combined free vibration-ambient vibration response data recorded immediately after a train passage.

\subsection{Bridge description}

The Jalón viaduct (Figure 6) is a six-span box girder prestressed concrete bridge for high-speed trains at Calatayud, Spain. The total length of the viaduct is $250 \mathrm{~m}$. The first span measures $35 \mathrm{~m}$; it is

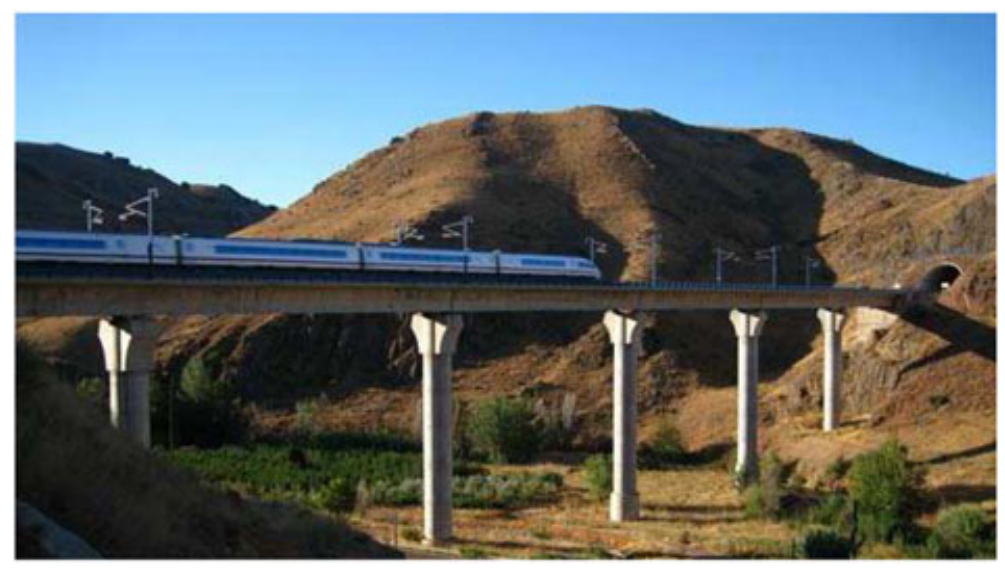

Figure 6. The Jalón viaduct. 
followed by four spans of $45 \mathrm{~m}$ each. The final span also measures $35 \mathrm{~m}$. The height of the intermediate piers varies from 27 to $38 \mathrm{~m}$. The bridge deck is $12.94 \mathrm{~m}$ wide. There are two parallel railway tracks running in opposite directions.

\subsection{Ambient vibration test}

To determine the dynamic properties of the Jalón viaduct and also to gather useful information for constructing a permanent health monitoring system, an ambient vibration test campaign was performed. The whole test was performed with 12 wireless triaxial accelerometers (GeoSIG GMS-18), which are interconnected through a time-synchronous WIFI network. The sampling frequency is $200 \mathrm{~Hz}$, and the sampling time for each setup is around $15 \mathrm{~min}$. In total, 303 nodes were measured in 38 different setups. All measurements were performed inside the box girder. Figure 7 shows the location of the measurement nodes. Among them, four reference nodes $(27,39,105$, and 139) were measured in all setups. So in each setup, the triaxial accelerations of four reference nodes and eight roving nodes were recorded (Figure 8).

\subsection{Operational modal analysis}

Operational modal analysis of the Jalón viaduct is performed using the MATLAB (MathWorks 3 Apple Hill Drive Natick, Massachusetts 01760 USA) toolbox MACEC 3.2 [32] developed by the Structural Mechanics Section of KU Leuven. Both the set of pure ambient vibration data and the set of combined free-ambient vibration data were used for modal parameter estimation. The condition of the viaduct immediately after train passage is considered as the initial condition. The modal parameters identified from pure ambient data have been presented previously by He et al. [33]. This paper will mainly focus on applying the combined free-ambient vibration data to the OMA of Jalón viaduct and aims to study the effects of the initial conditions in OMA. The ambient results will only serve as a comparison.

In a real vibration test, the free vibration is always accompanied by ambient excitation. From the simulation example, where all identification assumptions were satisfied, it was concluded that we can extract more accurate modal parameters from the combined free-ambient vibration data. It also suggested how to choose the sampling time after setting an accuracy criterion of the relative standard deviation of modal parameters. In this application, we will also investigate the effect of the

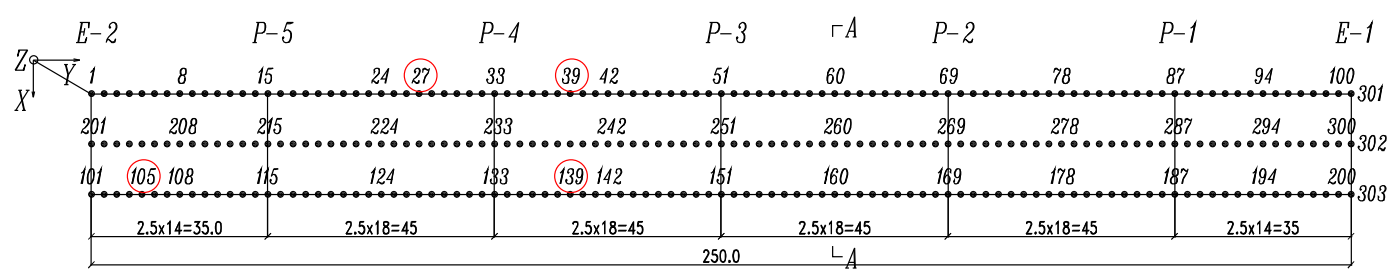

Figure 7. Location of measurement nodes. Units are in meters, and the circles indicate the reference nodes.

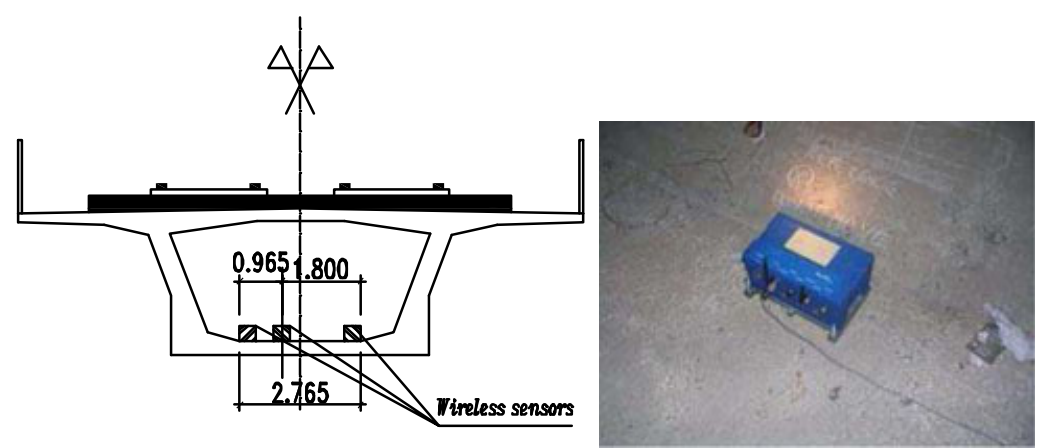

Figure 8. Sensor locations inside the box girder at (left) section A-A and (right) a wireless sensor in operation. 
measurement duration on the accuracy of the identified modal parameters. The results obtained are then compared with the ones from the simulation example.

Figures 9 and 10 plot the relative accuracy of the natural frequencies and damping ratios of the first two modes, obtained by computing sample means and variances over the 38 setups, as a function of the measurement duration. The legend ambient in the figure means the modal parameters are extracted from pure ambient data. The combine legend means that the corresponding modal parameters are extracted from combining pure ambient and free vibration data. As the real test data are influenced by many factors, the results are not as clear as in the mathematical simulation, but nevertheless, they are similar. For the results extracted from pure ambient data, the relative accuracy is always increasing with the measurement duration. For the results extracted from combined ambient and free vibration data, the contraflexure point, which indicates that the ambient data start to play dominant role, appears in the time range of $60-100 \mathrm{~s}$. The amplitude ratio $R$ of the free vibration data and the ambient data as defined in Equation (13) is around 80. According to the simulation results of Figure 4, 350 times the eigenperiod of the fundamental mode, which corresponds to a measurement duration of $55 \mathrm{~s}$, should be considered to reach a relative accuracy of 0.05 . So a data record of about $60 \mathrm{~s}$ will be used for the OMA of the Jalón viaduct with the combined free-ambient data.

Figure 11 shows the response recorded by a reference sensor under pure ambient and combined free-ambient vibration. Before using the two types of vibration responses for system identification, the data are preprocessed as follows. First, the data are sent through a high-pass filter with a cutoff frequency of $0.1 \mathrm{~Hz}$. Then, the constant offset is removed. Finally, a downsampling is performed by first low-pass filtering the data using a filter with a cutoff frequency of $48 \mathrm{~Hz}$ and then resampling the data at $60 \mathrm{~Hz}$
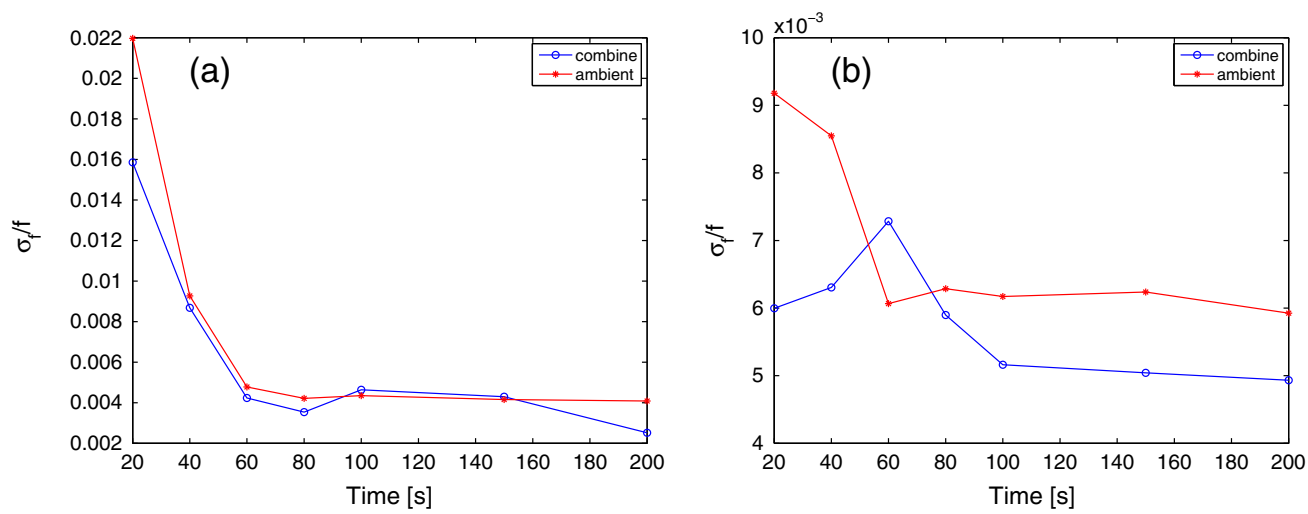

Figure 9. The relative accuracy of eigenfrequencies in function of the measurement duration. (a) Modes 1 and (b) 2.
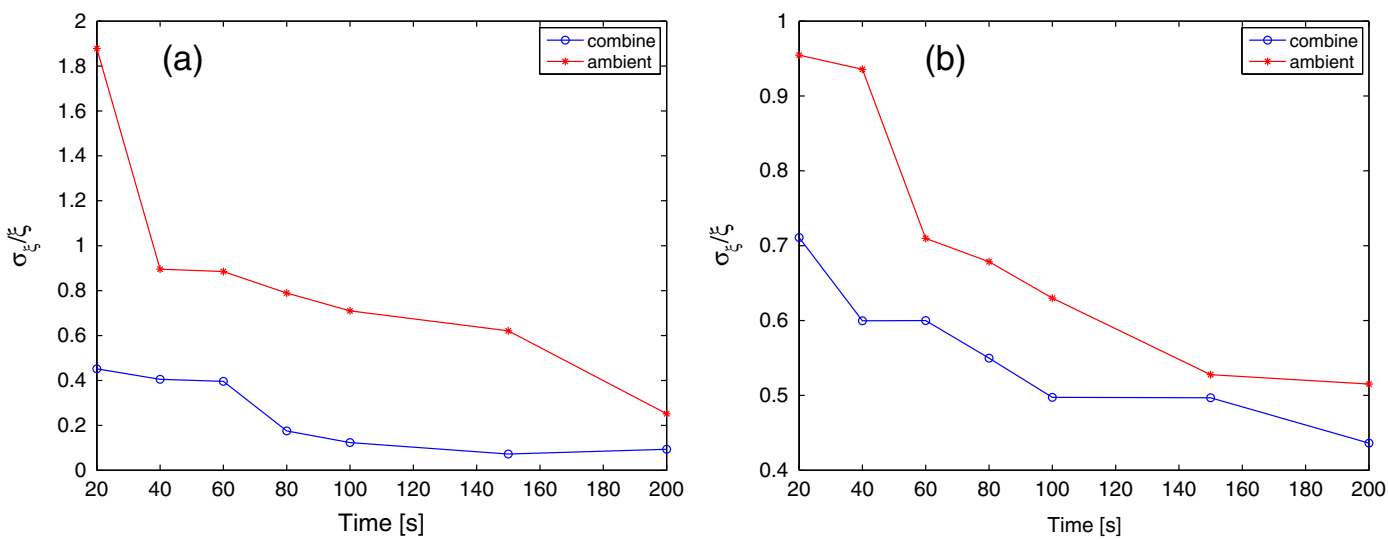

Figure 10. The relative accuracy of damping ratios in function of the measurement duration. (a) Modes 1 and (b) 2. 

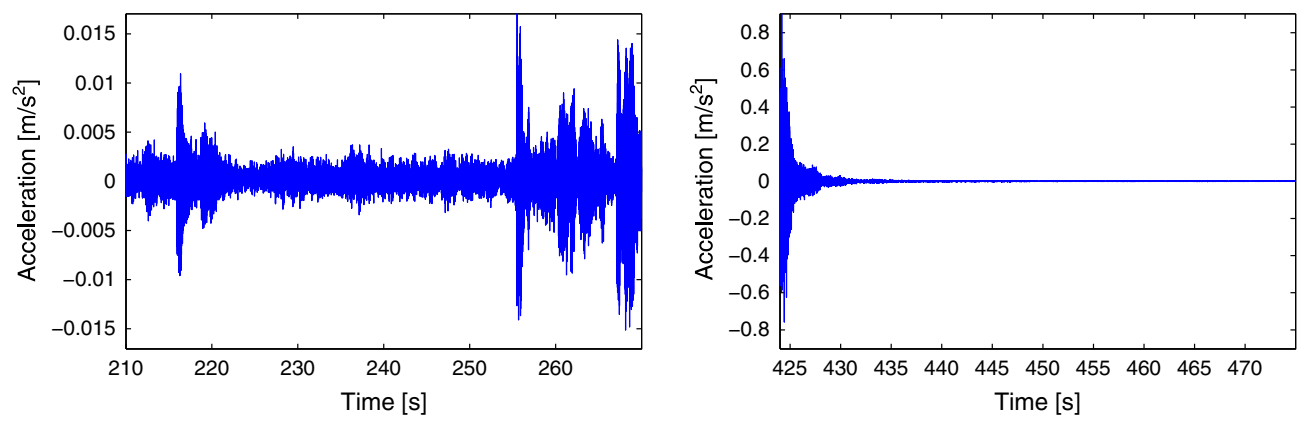

Figure 11. Typical acceleration time history of one reference sensor under (left) ambient excitation and (right) free vibration immediately after a train passage.

System identification was performed by the covariance-driven SSI algorithm [25]. A value of $i=115$ was selected for half the number of block rows. The model order was varied from 2 to 250 in steps of 2 to construct the stabilization diagrams [34]. The stabilization criteria are as follows: the difference in two successive natural frequencies $d f_{i} \leqslant 1 \%$, the difference in two successive damping ratios $d \xi_{i} \leqslant 5 \%$, modal assurance criteria (MAC) value between two successive mode shapes MAC $\leqslant 1 \%$, and the modal phase collinearity (MPC) larger than 0.5 . Figure 12 plots the stabilization diagram of the second setup obtained from pure ambient and combined free-ambient vibration data. The diagram constructed from the combined free-ambient data contains more stable poles in the frequency range of $6-10 \mathrm{~Hz}$, which means that more modes can be identified in this frequency range.

Table I summarizes the modal parameters of the Jalón viaduct identified from combined freeambient and pure ambient vibration data. The mean values and the standard deviations are the finitesample estimates obtained over all 38 setups. The frequencies and damping ratios extracted from pure ambient data are also listed. Of the identified 18 modes, 7 are lateral bending, 9 are vertical bending, and 2 are torsion.

Only 11 of these modes can also be extracted from the pure ambient data. The other seven modes, which are usually the higher bending and torsion modes, can only be extracted from the combined free-ambient vibration data. The standard deviations of the eigenfrequencies and damping ratios are relatively small, which means that all the identified modes of the viaduct are well identified in each setup. The MPC values are very close to 1 , which means that the identified mode shapes are almost purely real. A comparison between the ambient and free vibration results with respect to eigenfrequencies, damping ratios, and standard deviation of eigenfrequencies and damping ratios is shown in Figure 13. The relative differences in eigenfrequency between ambient and free vibration
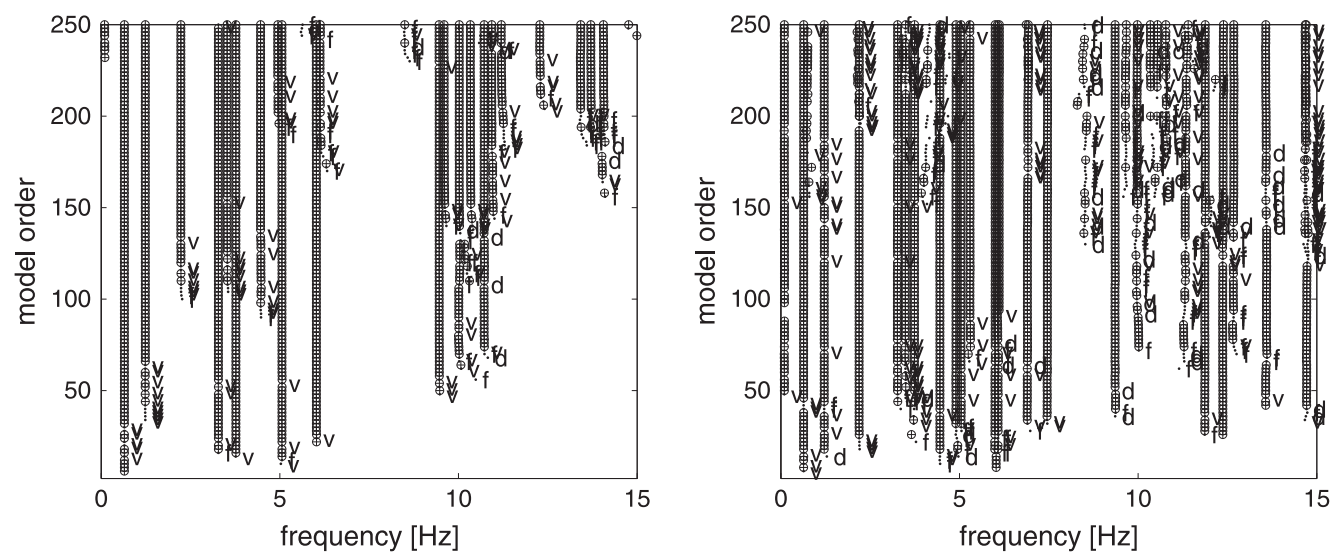

Figure 12. The stabilization diagram of setup 2 obtained from (left) pure ambient data and (right) free vibration data. $\oplus$, stable poles; v, stable frequency and vector; d, stable frequency and damping; .f, stable frequency. Stabilization criteria: $\mathbf{d} f_{i} \leqslant 1 \%, \mathbf{d} \xi_{i} \leqslant 5 \%$, and MAC $\leqslant 1 \%$. 
Table I. Summary of the experimental results obtained from the combined free-ambient and purely ambient vibration data.

\begin{tabular}{|c|c|c|c|c|c|c|c|c|}
\hline \multirow[t]{2}{*}{ Mode } & \multicolumn{5}{|c|}{ Free vibration } & \multicolumn{2}{|c|}{ Ambient vibration } & \multirow[t]{2}{*}{ Type } \\
\hline & $f_{f}(\mathrm{~Hz})$ & $\sigma_{f_{f}}$ & $\xi_{f}(\%)$ & $\xi_{a}(\%)$ & MPC & $f_{a}(\mathrm{~Hz})$ & $\xi_{f_{a}}(\%)$ & \\
\hline 1 & 0.648 & 0.029 & 0.69 & 0.67 & 0.94 & 0.648 & 0.75 & $1 \mathrm{st} \leftrightarrow$ \\
\hline 2 & 1.219 & 0.008 & 1.34 & 1.51 & 0.96 & 1.238 & 0.81 & $2 \mathrm{nd} \leftrightarrow$ \\
\hline 3 & 2.186 & 0.035 & 1.53 & 1.87 & 0.85 & 2.230 & 1.00 & $3 \mathrm{rd} \leftrightarrow$ \\
\hline 4 & 3.267 & 0.003 & 0.40 & 0.11 & 0.96 & 3.279 & 0.42 & $1 \mathrm{st} \uparrow$ \\
\hline 5 & 3.493 & 0.009 & 0.70 & 0.14 & 0.93 & 3.536 & 1.37 & 4 th $\leftrightarrow$ \\
\hline 6 & 3.783 & 0.027 & 0.61 & 0.55 & 0.98 & 3.758 & 0.54 & $2 \mathrm{nd} \uparrow$ \\
\hline 7 & 4.094 & 0.025 & 1.74 & 0.83 & 0.87 & $\mathrm{n} / \mathrm{a}$ & $\mathrm{n} / \mathrm{a}$ & $3 \mathrm{rd} \uparrow$ \\
\hline 8 & 4.452 & 0.004 & 0.48 & 0.07 & 0.98 & 4.471 & 0.66 & $4 \operatorname{th} \uparrow$ \\
\hline 9 & 4.917 & 0.011 & 0.74 & 0.09 & 0.94 & $\mathrm{n} / \mathrm{a}$ & $\mathrm{n} / \mathrm{a}$ & 5 th $\leftrightarrow$ \\
\hline 10 & 5.045 & 0.013 & 0.62 & 0.47 & 0.97 & 5.056 & 0.57 & $5 \operatorname{th} \uparrow$ \\
\hline 11 & 5.309 & 0.028 & 0.73 & 0.47 & 0.85 & $\mathrm{n} / \mathrm{a}$ & $\mathrm{n} / \mathrm{a}$ & $1 \mathrm{st} \cup$ \\
\hline 12 & 6.027 & 0.034 & 0.70 & 0.15 & 0.91 & 6.036 & 0.69 & $6 \operatorname{th} \uparrow$ \\
\hline 13 & 7.455 & 0.061 & 0.70 & 0.20 & 0.87 & $\mathrm{n} / \mathrm{a}$ & $\mathrm{n} / \mathrm{a}$ & 6th↔ \\
\hline 14 & 8.420 & 0.036 & 0.96 & 0.62 & 0.83 & $\mathrm{n} / \mathrm{a}$ & $\mathrm{n} / \mathrm{a}$ & $2 \mathrm{nd} \cup$ \\
\hline 15 & 9.329 & 0.138 & 0.96 & 0.29 & 0.79 & $\mathrm{n} / \mathrm{a}$ & $\mathrm{n} / \mathrm{a}$ & 7 th $\leftrightarrow$ \\
\hline 16 & 10.435 & 0.114 & 0.95 & 0.43 & 0.65 & 10.011 & 0.82 & $7 \operatorname{th} \uparrow$ \\
\hline 17 & 10.746 & 0.071 & 1.39 & 2.28 & 0.56 & 10.743 & 0.69 & $8 \operatorname{th} \uparrow$ \\
\hline 18 & 14.694 & 0.066 & 0.95 & 0.25 & 0.82 & $\mathrm{n} / \mathrm{a}$ & $\mathrm{n} / \mathrm{a}$ & $9 \operatorname{th} \uparrow$ \\
\hline
\end{tabular}

$\leftrightarrow$, lateral bending mode; $\uparrow$, vertical bending mode; $\circlearrowleft$, torsion mode; MPC, modal phase collinearity; n/a, not applicable.
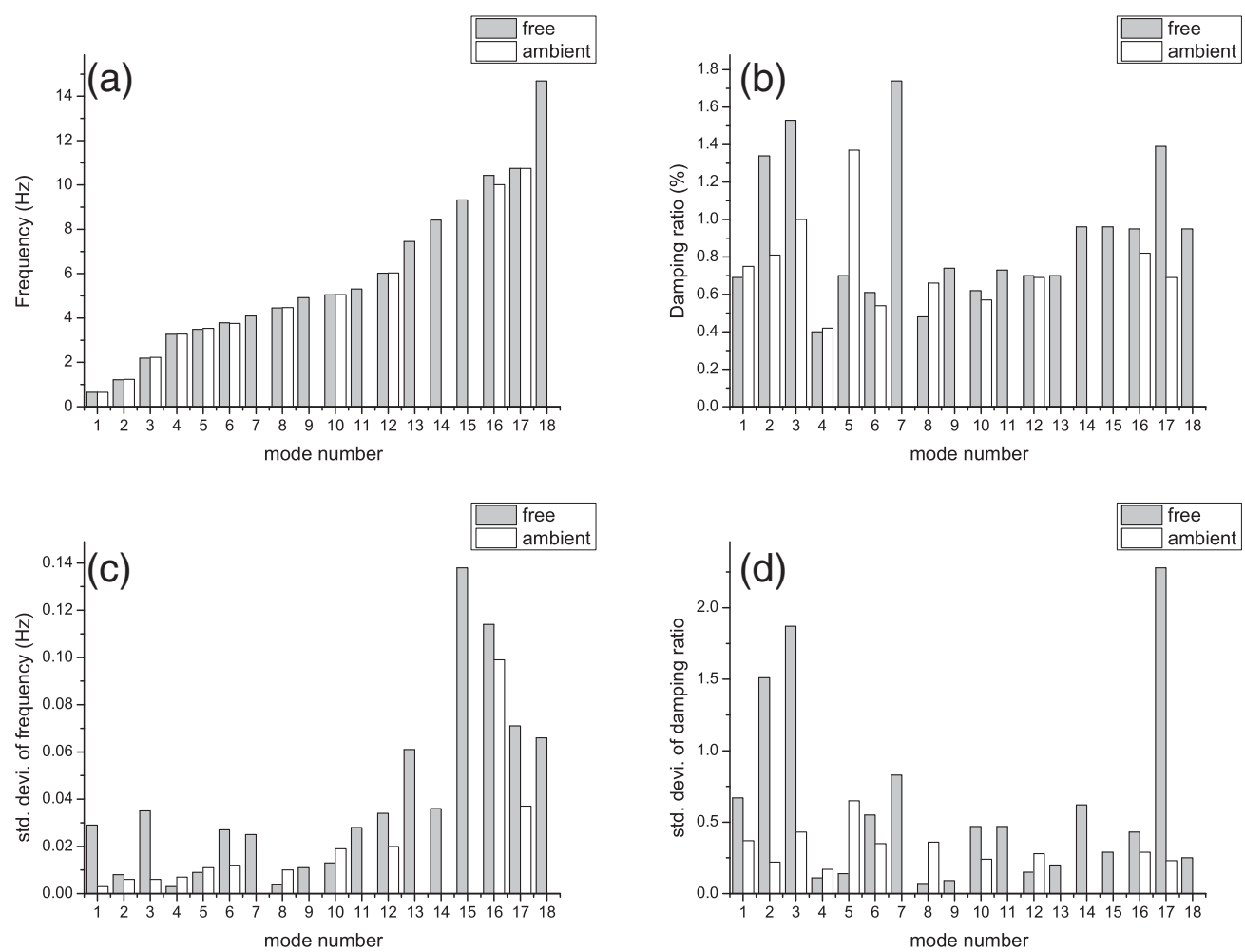

Figure 13. Comparison between the modal parameters identified obtained from purely ambient and combined free-ambient data: (a) eigenfrequencies, (b) damping ratios, (c) standard deviation of eigenfrequencies, and (d) standard deviation of damping ratios. 
results are very small, whereas the relative differences for the damping ratios are much larger. The standard deviations of the eigenfrequencies and damping ratios extracted from combined freeambient vibration data are usually larger than the ones extracted from purely ambient vibration data.

The 3D mode shapes of the identified lateral and vertical bending modes are plotted in Figures 14 and 15, respectively. The modes that can only be extracted from the combined free-ambient vibration data are shown in Figure 16. The MPC values, which are an indicator for the smoothness of the mode shapes, are also included in these figures. The higher bending and torsion modes have usually a lower MPC value, reflected also by some irregularities in the mode shapes.

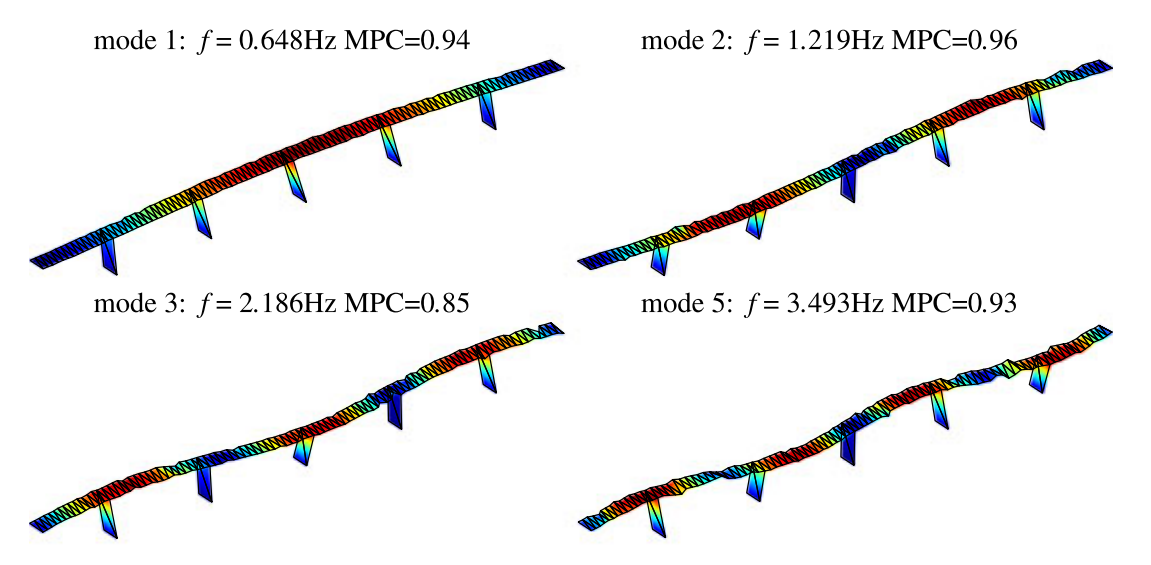

Figure 14. Jalón viaduct: identified lateral bending modes from combined free-ambient vibration data. MPC, modal phase collinearity.

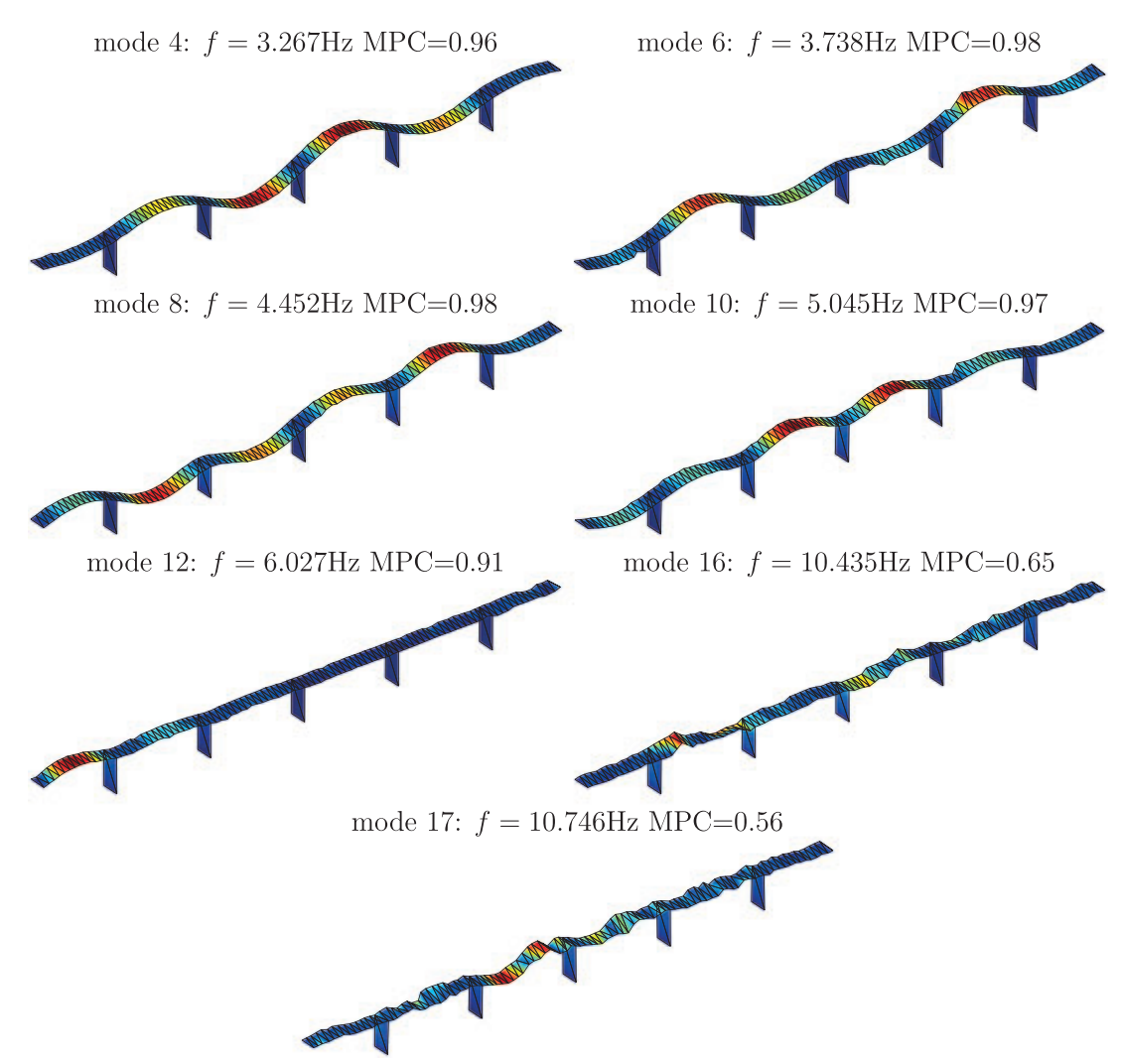

Figure 15. Jalón viaduct: identified vertical bending modes from combined free-ambient vibration data. MPC, modal phase collinearity. 

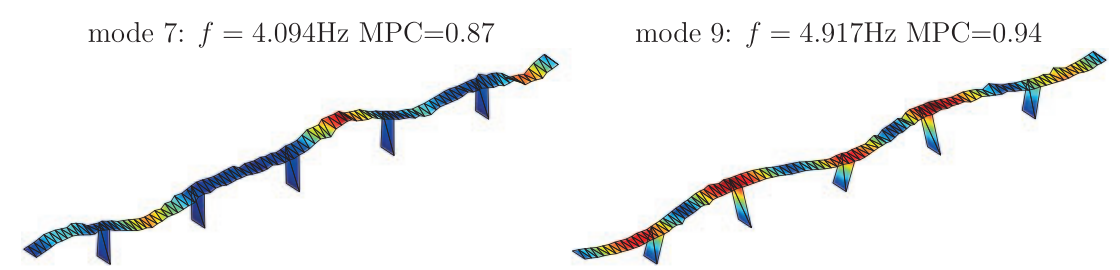

mode 11: $f=5.309 \mathrm{~Hz} \mathrm{MPC}=0.85$

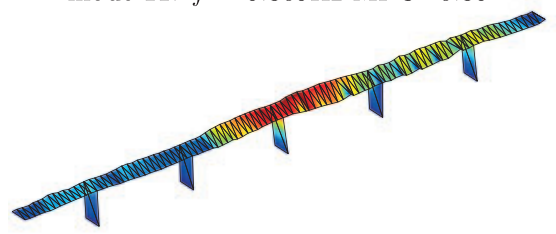

$$
\text { mode 13: } f=7.455 \mathrm{~Hz} \mathrm{MPC}=0.87
$$

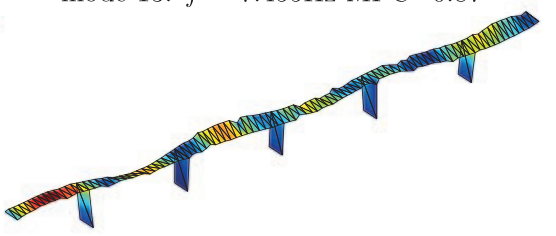

mode 14: $f=8.420 \mathrm{~Hz} \mathrm{MPC}=0.83$

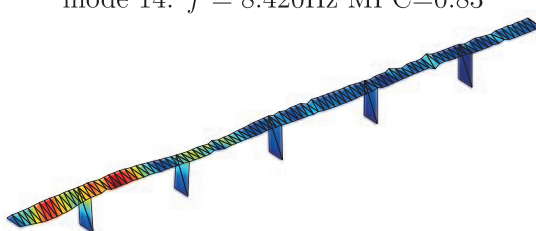

mode 15: $f=9.329 \mathrm{~Hz} \mathrm{MPC}=0.79$

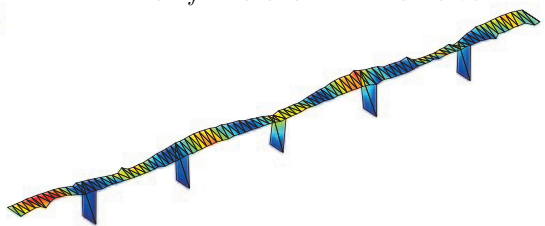

mode 18: $f=14.694 \mathrm{~Hz} \mathrm{MPC}=0.82$

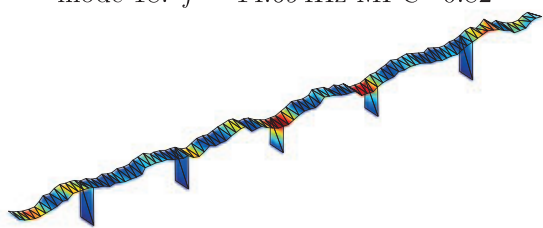

Figure 16. The higher modes that can only be extracted from the combined free-ambient vibration data. MPC, modal phase collinearity.

\subsection{Finite element analysis}

A 3D finite element (FE) model was constructed to further validate the experimental results. The FE model (Figure 17) was built in ANSYS (ANSYS, Inc 2855 Telegraph Avenue, Suite 501 Berkeley, CA 94705) by using Beam 4 elements for the piers and Solid 45 elements for the box girder and the ballast. The material properties of box girder and piers were determined from the design documents. As material properties of ballast, the following values were adopted from the literature [35]: a Young's modulus of $280 \mathrm{MPa}$, a Poisson's ratio of 0.3 , and a density of $17000 \mathrm{~kg} / \mathrm{m}^{3}$.

Table II compares the analytical and experimental results. Overall, a good match is found between the analytical and experimental results. The relative differences between the eigenfrequencies calculated from the FE model and the corresponding values identified from the combined free-ambient data are usually larger than the relative differences between the eigenfrequencies computed from the FE model and the corresponding values identified from the purely ambient data.

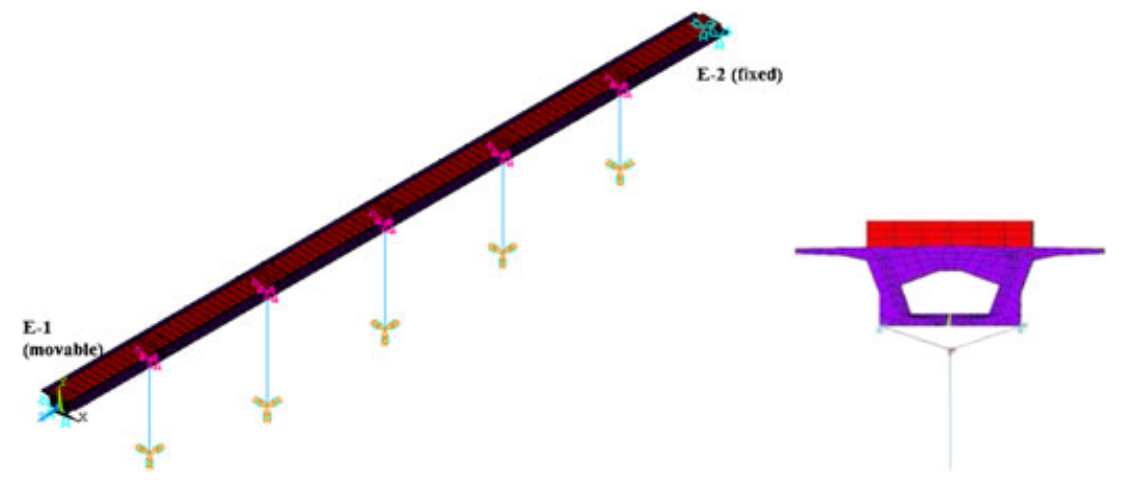

Figure 17. Finite element model (FEM) of the Jalón viaduct. 
Table II. Comparison of finite element and experimental results.

\begin{tabular}{|c|c|c|c|c|c|c|c|}
\hline \multirow[t]{2}{*}{ Mode } & \multirow{2}{*}{$\frac{\mathrm{FEM}}{f_{e}(\mathrm{~Hz})}$} & \multirow{2}{*}{$\begin{array}{c}\text { Free } \\
f_{a}(\mathrm{~Hz})\end{array}$} & \multirow{2}{*}{$\frac{\text { Ambient }}{f_{f}(\mathrm{~Hz})}$} & \multicolumn{3}{|c|}{ Comparison } & \multirow[t]{2}{*}{ Type } \\
\hline & & & & $\Delta f_{e f}(\%)$ & $\Delta f_{e a}(\%)$ & $\Delta f_{f a}(\%)$ & \\
\hline 1 & 0.601 & 0.648 & 0.648 & 7.25 & 7.25 & 0.00 & $1 \mathrm{st} \leftrightarrow$ \\
\hline 2 & 1.182 & 1.219 & 1.238 & 4.52 & 3.04 & -1.53 & $2 \mathrm{nd} \leftrightarrow$ \\
\hline 3 & 2.201 & 2.186 & 2.230 & 1.30 & -0.69 & -1.97 & $3 \mathrm{rd} \leftrightarrow$ \\
\hline 4 & 3.264 & 3.267 & 3.279 & 0.46 & 0.09 & -0.37 & $1 \mathrm{st} \uparrow$ \\
\hline 5 & 3.595 & 3.493 & 3.536 & -1.67 & -2.92 & -1.22 & 4th↔ \\
\hline 6 & 3.788 & 3.783 & 3.758 & -0.80 & -0.13 & 0.67 & $2 \mathrm{nd} \uparrow$ \\
\hline 7 & $\mathrm{n} / \mathrm{a}$ & 4.094 & $\mathrm{n} / \mathrm{a}$ & n/a & $\mathrm{n} / \mathrm{a}$ & $\mathrm{n} / \mathrm{a}$ & $3 \mathrm{rd} \uparrow$ \\
\hline 8 & 4.421 & 4.452 & 4.471 & 1.12 & 0.70 & -0.42 & $4 \operatorname{th} \uparrow$ \\
\hline 9 & 5.211 & 4.917 & $\mathrm{n} / \mathrm{a}$ & $\mathrm{n} / \mathrm{a}$ & -5.98 & $\mathrm{n} / \mathrm{a}$ & 5 th $\leftrightarrow$ \\
\hline 10 & 5.015 & 5.045 & 5.056 & 0.81 & 0.59 & -0.22 & 5 th $\uparrow$ \\
\hline 11 & 5.717 & 5.309 & $\mathrm{n} / \mathrm{a}$ & $\mathrm{n} / \mathrm{a}$ & -7.69 & n/a & $1 \mathrm{st} \cup$ \\
\hline 12 & 5.966 & 6.027 & 6.036 & 1.16 & 1.01 & -0.15 & 6 th $\uparrow$ \\
\hline 13 & 7.554 & 7.455 & $\mathrm{n} / \mathrm{a}$ & $\mathrm{n} / \mathrm{a}$ & -1.33 & $\mathrm{n} / \mathrm{a}$ & 6 th $\leftrightarrow$ \\
\hline 14 & 9.290 & 8.420 & $\mathrm{n} / \mathrm{a}$ & $\mathrm{n} / \mathrm{a}$ & -10.33 & $\mathrm{n} / \mathrm{a}$ & $2 \mathrm{nd} \cup$ \\
\hline 15 & 10.180 & 9.329 & $\mathrm{n} / \mathrm{a}$ & $\mathrm{n} / \mathrm{a}$ & -9.12 & $\mathrm{n} / \mathrm{a}$ & 7 th↔ \\
\hline 16 & 10.190 & 10.435 & 10.011 & -1.79 & 2.35 & 4.24 & 7 th $\uparrow$ \\
\hline 17 & 10.971 & 10.746 & 10.743 & -2.12 & -2.09 & 0.03 & $8 \operatorname{th} \uparrow$ \\
\hline 18 & 15.739 & 14.694 & $\mathrm{n} / \mathrm{a}$ & $\mathrm{n} / \mathrm{a}$ & -7.11 & $\mathrm{n} / \mathrm{a}$ & $9 \operatorname{th} \uparrow$ \\
\hline
\end{tabular}

$\Delta f_{e a}=\left(f_{a}-f_{e}\right) / f_{a} \times 100 \%, \Delta f_{e f}=\left(f_{f}-f_{e}\right) / f_{f} \times 100 \%, \Delta f_{f a}=\left(f_{f}-f_{a}\right) / f_{a} \times 100 \% . \leftrightarrow$, lateral bending mode; $\uparrow$, vertical bending mode; $U$, torsion; FEM, finite element model; n/a, not applicable.

Mode 1: $f_{f}=0.648 \mathrm{~Hz}, \mathrm{MAC}=0.973$

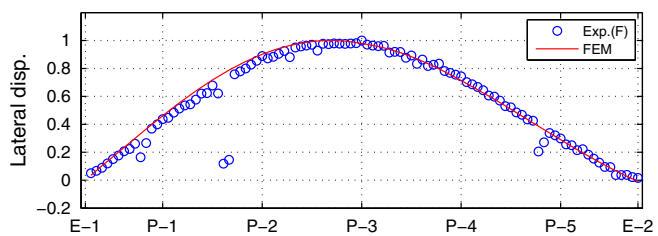

Mode 3: $f_{f}=2.186 \mathrm{~Hz}, \mathrm{MAC}=0.926$

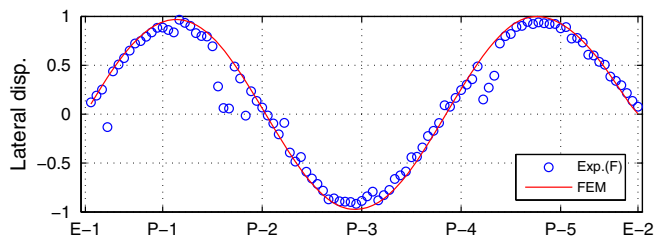

Mode 9: $f_{f}=4.917 \mathrm{~Hz}, \mathrm{MAC}=0.958$

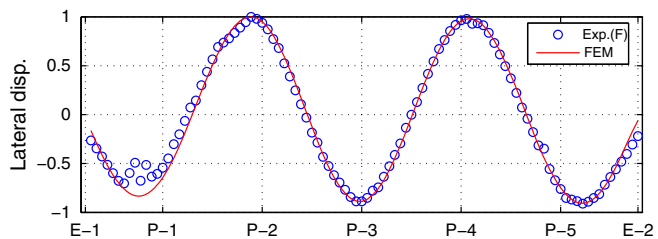

Mode $\mathrm{F} 15 \cdot f_{f}=9.329 \mathrm{~Hz} \quad \mathrm{MAC}=0.649$

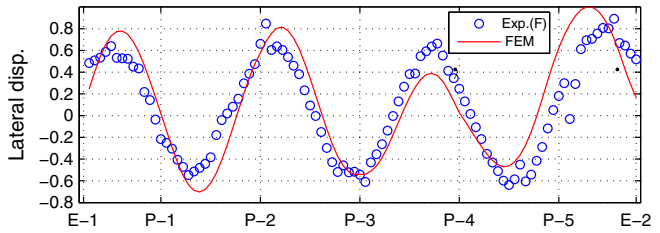

Mode 2: $f_{f}=1.219 \mathrm{~Hz}, \mathrm{MAC}=0.977$

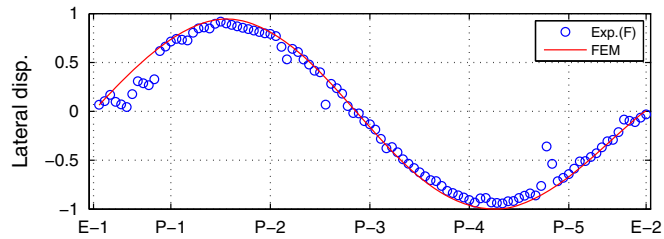

Mode 5: $f_{f}=3.493 \mathrm{~Hz}, \mathrm{MAC}=0.964$

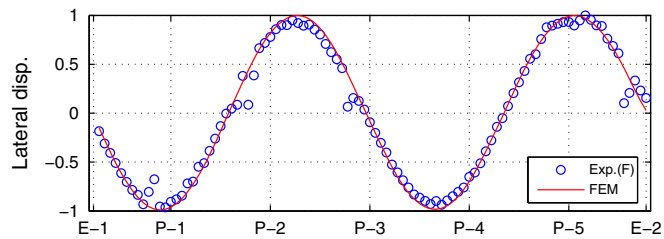

Mode 13: $f_{f}=7.455 \mathrm{~Hz}, \mathrm{MAC}=0.499$

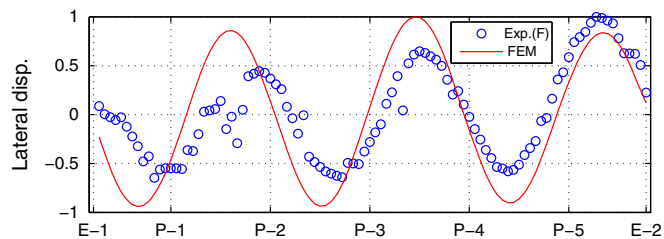

Figure 18. Comparison of computed mode shapes and the mode shapes identified from the combined freeambient data: Lateral bending modes. FEM, finite element model; MAC, modal assurance criteria. 
The computed and experimentally determined modal displacements are compared in Figures 18-20 for lateral bending, vertical bending, and torsion modes, respectively. The experimental modal displacements are plotted along one of the measurement lines (from nodes 1 to 303, see Figure 7).

Mode 4: $f_{f}=3.267 \mathrm{~Hz}, \mathrm{MAC}=0.985$

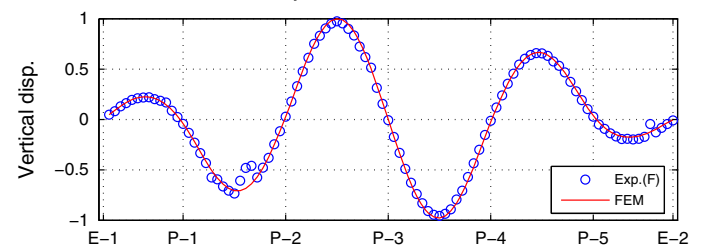

Mode 8: $f_{f}=4.452 \mathrm{~Hz}, \mathrm{MAC}=0.969$

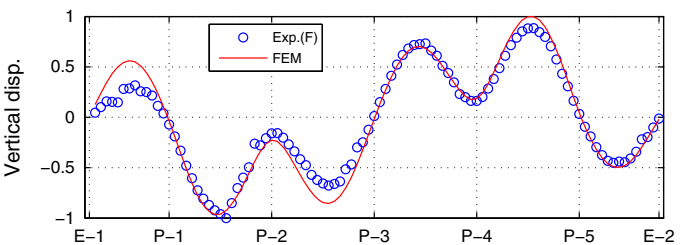

Mode 12: $f_{f}=7.455 \mathrm{~Hz}, \mathrm{MAC}=0.911$

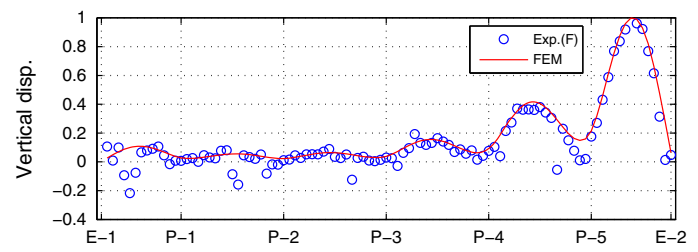

Mode 17: $f_{f}=6.027 \mathrm{~Hz}, \mathrm{MAC}=0.458$

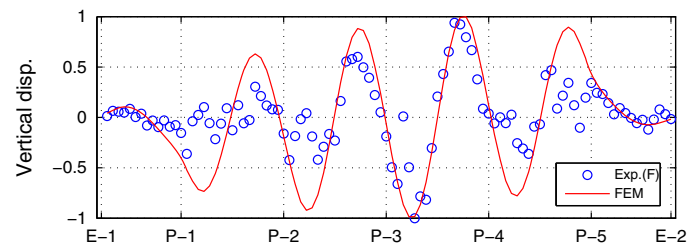

Mode 6: $f_{f}=3.783 \mathrm{~Hz}, \mathrm{MAC}=0.986$

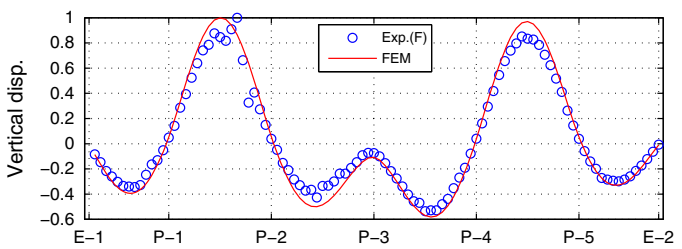

Mode 10: $f_{f}=5.045 \mathrm{~Hz}, \mathrm{MAC}=0.969$

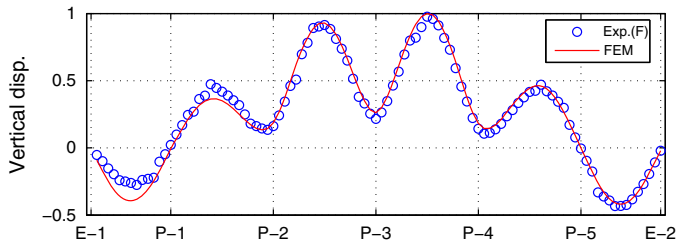

Mode 16: $f_{f}=7.455 \mathrm{~Hz}, \mathrm{MAC}=0.072$

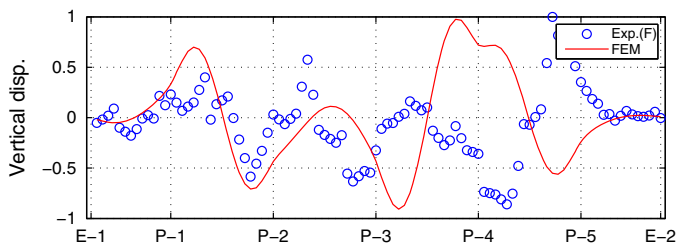

Mode 18: $f_{f}=14.694 \mathrm{~Hz}, \mathrm{MAC}=0.720$

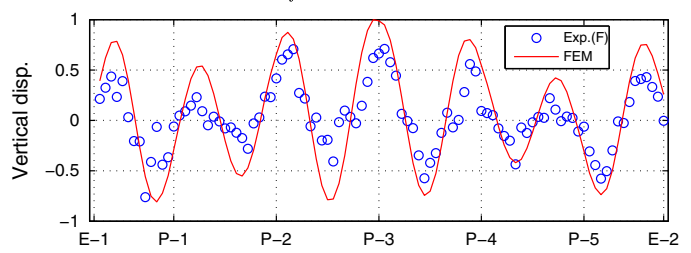

Figure 19. Comparison of computed mode shapes and the mode shapes identified from the combined freeambient data: Vertical bending modes. FEM, finite element model; MAC, modal assurance criteria.
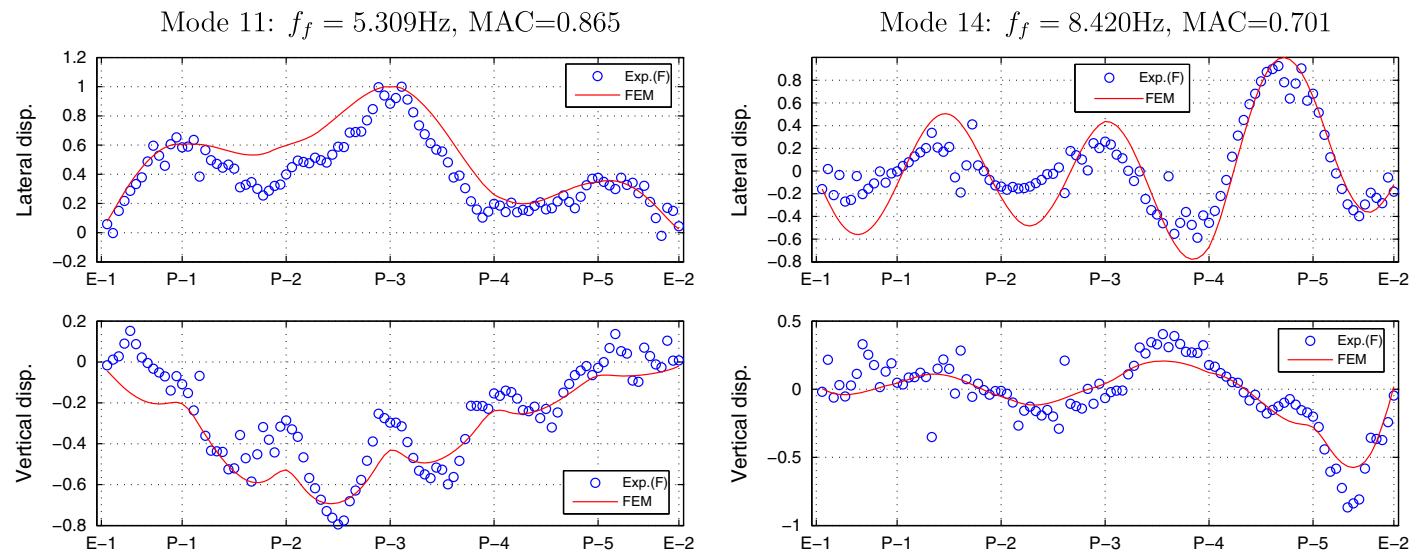

Figure 20. Comparison of computed mode shapes and the mode shapes identified from the combined freeambient data: Torsion modes. The top one is lateral modal displacement, whereas the bottom one is vertical modal displacement. FEM, finite element model; MAC, modal assurance criteria. 
The MAC values calculated between the FE results and the experimental results are also shown in these figures. These MAC values are high (often $>0.95$ ) for the vertical and lateral bending modes that can be identified from both the purely ambient and combined free-ambient data. For the torsion and higher bending modes that can be identified from the combined free-ambient data only, the MAC values are lower. This does not necessarily mean that these modes are less well identified from the measured vibration data; it may as well be that the FE model is less able to predict these modes with good accuracy.

\section{CONCLUSIONS}

In this paper, the effect of large-amplitude initial conditions on OMA results was studied. The influence on the sample output correlation function, which is the basis of most time-domain OMA techniques including SSI, was analyzed analytically. The influence on the accuracy of the identified modal parameters was investigated in a simulation example and a full-scale application of the six-span railway viaduct. The following conclusions can be drawn from this study.

When all identification assumptions are satisfied, the estimation error of the output correlation sequence decreases when the measurement duration increases, and the ratio between the maximum of the free vibration response and the RMS value of the ambient response increases. The positive influence of the initial conditions is more pronounced for short data sequences. The results of the simulation example provide a way to decide, for a given free/ambient response ratio, what the measurement duration needs to be in order to reach the desired estimation accuracy.

The OMA of the Jalón viaduct shows that both purely ambient and combined free-ambient data provide reliable experimental modal results. Because the purely ambient response is narrow banded in the frequency domain, the higher bending and torsion modes could only be extracted from the combined free-ambient data, which were obtained immediately after a train passage.

\section{ACKNOWLEDGEMENTS}

The bridge vibration tests reported in this work have been performed in the framework of the VIADINTEGRA project (grant no. ORDEN CIN/1337/2010) funded by the Spanish Ministry of Science and Innovation (sub-program INNPACTO 2010) and ERDF funds. The first author acknowledges the financial support from the China Scholarship Council (CSC) (grant no. 2011700032). E. Reynders is a postdoctoral fellow of the Research Foundation - Flanders (FWO), Belgium. The financial support of FWO is gratefully acknowledged. E. Reynders and G. De Roeck are members of KU Leuven-BOF PFV/10/002 OPTEC-Optimization in Engineering Center of Excellence.

\section{REFERENCES}

1. Ko J, Ni Y. Technology developments in structural health monitoring of large-scale bridges. Engineering Structures 2005; 27(12):1715-1725.

2. Hsieh K, Halling M, Barr P, et al. Overview of vibrational structural health monitoring with representative case studies. Journal of Bridge Engineering 2006; 11(6):707.

3. Brownjohn J. Structural health monitoring of civil infrastructure. Philosophical Transactions of the Royal Society A: Mathematical, Physical and Engineering Sciences 2007; 365(1851):589-622.

4. Reynders E, De Roeck G, Bakir P, Sauvage C. Damage identification on the Tilff bridge by vibration monitoring using optical fibre strain sensors. Journal of Engineering Mechanics 2007; 133(2):185-193.

5. Deraemaeker A, Reynders E, De Roeck G, Kullaa J. Vibration-based structural health monitoring using output-only measurements under changing environment. Mechanical Systems and Signal Processing 2008; 22(1):34-56.

6. Reynders E, Teughels A, De Roeck G. Finite element model updating and structural damage identification using OMAX data. Mechanical Systems and Signal Processing 2010; 24(5):1306-1323.

7. Peeters B, De Roeck G. One-year monitoring of the Z24 bridge: environmental effects versus damage events. Earthquake Engineering and Structural Dynamics 2001; 30(2):149-171.

8. Magalhães F, Cunha Á, Caetano E. Dynamic monitoring of a long span arch bridge. Engineering Structures 2008; 30(11):3034-3044.

9. Chan T, Yu L, Tam H, Ni Y, Liu S, Chung W, Cheng L. Fiber Bragg grating sensors for structural health monitoring of Tsing Ma bridge: background and experimental observation. Engineering Structures 2006; 28(5):648-659.

10. Lau C, Mak W, Wong K, Chan W, Man K. Structural health monitoring of three cable-supported bridges in Hong Kong. In Structural Health Monitoring, Chang FK (ed.). Technomic: Lancaster (PA), 1999; 450-460.

11. Farrar C, Cornwell P, Doebling S, Prime M. Structural health monitoring studies of the Alamosa Canyon and I-40 bridges. Technical report, Los Alamos National Lab., NM (US), 2000. 
12. Jang S, Jo H, Cho S, Mechitov K, Rice J, Sim S, Jung H, Yun C, Spencer B Jr, Agha G. Structural health monitoring of a cable-stayed bridge using smart sensor technology: deployment and evaluation. Smart Structures and Systems 2010; 6(5-6):439-459.

13. Ni Y, Xia Y, Liao W, Ko J. Technology innovation in developing the structural health monitoring system for Guangzhou New TV Tower. Structural Control and Health Monitoring 2009; 16(1):73-98.

14. Kim J, Stubbs N. Improved damage identification method based on modal information. Journal of Sound and Vibration 2002; 252(2):223-238.

15. Hermans L, van der Auweraer H. Modal testing and analysis of structures under operational conditions: industrial applications. Mechanical Systems and Signal Processing 1999; 13(2):193-216.

16. Magalhães F, Caetano E, Cunha Á. Operational modal analysis and finite element model correlation of the Braga Stadium suspended roof. Engineering Structures 2008; 30(6):1688-1698.

17. Reynders E, Roeck G. Reference-based combined deterministic-stochastic subspace identification for experimental and operational modal analysis. Mechanical Systems and Signal Processing 2008; 22(3):617-637.

18. Altunisik A, Bayraktar A, Sevim B, Özdemir H. Experimental and analytical system identification of Eynel arch type steel highway bridge. Journal of Constructional Steel Research 2008; 67:1912-1921.

19. Reynders E. System identification methods for (operational) modal analysis: review and comparison. Archives of Computational Methods in Engineering 2012; 19(1):51-124.

20. Reynders E, Degrauwe D, De Roeck G, Magalhães F, Caetano E. Combined experimental-operational modal testing of footbridges. Journal of Engineering Mechanics 2010; 136(6):687-696.

21. Magalhães F, Cunha Á, Caetano E, Brincker R. Damping estimation using free decays and ambient vibration tests. Mechanical Systems and Signal Processing 2010; 24(5):1274-1290.

22. Magalhães F, Caetano E, Cunha Á, Flamand O, Grillaud G. Ambient and free vibration tests of the Millau Viaduct: evaluation of alternative processing strategies. Engineering Structures 2012; 45:372-384.

23. Cunha A, Caetano E, Delgado R. Dynamic tests on large cable-stayed bridge. Journal of Bridge Engineering 2001; 6(1):54-62.

24. Overschee P, De Moor B. Subspace Identification for the Linear Systems: Theory - Implementation - Applications. Kluwer Academic Publishers: Boston, 1996.

25. Peeters B, De Roeck G. Reference-based stochastic subspace identification for output-only modal analysis. Mechanical Systems and Signal Processing 1999; 13(6):855-878.

26. Reynders E, Pintelon R, De Roeck G. Uncertainty bounds on modal parameters obtained from stochastic subspace identification. Mechanical Systems and Signal Processing 2008; 22(4):948-969.

27. Peeters B, De Roeck G. Stochastic system identification for operational modal analysis: a review. Journal of Dynamic Systems, Measurement, and Control 2001; 123:659.

28. Yu D, Ren W. EMD-based stochastic subspace identification of structures from operational vibration measurements. Engineering Structures 2005; 27(12):1741-1751.

29. Fan J, Zhang Z, Hua H. Data processing in subspace identification and modal parameter identification of an arch bridge. Mechanical Systems and Signal Processing 2007; 21(4):1674-1689.

30. Mevel L, Basseville M, Goursat M. Stochastic subspace-based structural identification and damage detection-application to the steel-quake benchmark. Mechanical Systems and Signal Processing 2003; 17(1):91-101.

31. Sadeghi N, Fayek A, Pedrycz W. Fuzzy Monte Carlo simulation and risk assessment in construction. Computer-Aided Civil and Infrastructure Engineering 2009; 25(4):238-252.

32. Reynders E, Schevenels M, De Roeck G. MACEC 3.2: A MATLAB toolbox for experimental and operational modal analysis. Technical report, Technical Report bwm-2011-01, Department of Civil Engineering, KU Leuven, 2011.

33. He L, Qin S, Bui T, Reynders E, Cuadrado M, Museros P, De Roeck G. Operational modal analysis of a high-speed railway bridge: the Jalón viaduct. In ISMA International Conference on Noise and Vibration Engineering, Leuven, Belgium, 2012.

34. Reynders E, Houbrechts J, De Roeck G. Fully automated (operational) modal analysis. Mechanical Systems and Signal Processing 2012; 29:228-250.

35. Liu K. Analysis and monitoring of dynamic effects of train-bridge interaction. Ph.D. thesis, University of Leuven-KU Leuven, 2010. 